\title{
Female mate choice and male red coloration in a natural three-spined stickleback (Gasterosteus aculeatus) population
}

\section{Theo C. M. Bakker}

Beat Mundwiler

Universität Bern,

Zoologisches Institut,

Abt. Verhaltensökologie,

Wohlenst rasse 50a,

CH-8032 Hinterkappelen, Switzerland
Received 3 July 1992

Revised 10 December 1992

Accepted 19 December 1992

$1045-2249 / 94 / \$ 5.00$

(c) 1994 International Society for Behavioral Ecology

Under laboratory conditions, female three-spined sticklebacks (Gasterosteus aculeatus L.) show a mating preference for intensely red-colored males. We verified this female choice in the field by observing a freshwater stickleback population in its natural habitat. During the egg collection phase, individual courting males were localized with the aid of a dummy of a ripe female, caught and photographed under standardized conditions, and released. After males had stopped collecting eggs, we counted the number of eggs in the nests. The more intense a male's red breeding coloration, the more eggs he received. Simultaneous female choice experiments in the laboratory suggested that ripe females of this population preferred redder males. Breeding activities of the males in the field were clustered and seem to be synchronized within clusters. At one of the breeding sites, more intense red males were in better physical condition, but this was not the case at another site. Although several synchronized breeding cycles were observed, the majority of males seem to complete only one breeding cycle. Key words: breeding coloration, female choice, Gasterosteus aculeatus, sexual selection, three-spined sticklebacks. [Behav Ecol 5:74-80 (1994)]

$\mathrm{T}$ he three-spined stickleback is a small fish that shows conspicuous sexual dichromatism and paternal care during the breeding season; males develop a bright orange-red body coloration and blue-green eyes. One advantage of using the threespined stickleback (Gasterasterus aculeatus L.) as an experimental animal in behavioral ecology is that it can easily be studied both in its natural habitat and in the laboratory under seminatural conditions. Several determinants of male reproductive success have been identified in the field and/or in the laboratory: large male territory size, concealment of nests, low level of aggression, presence of eggs in the nest, and nesting early in the reproductive season (Goldschmidt and Bakker, 1990).

Recent experiments on female choice in the laboratory showed that females prefer more intensely red-colored males in simultaneous (McLennan, 1991; McLennan and McPhail, 1990; Milinski and Bakker, 1990) and sequential (Bakker and Milinski, 1991; Milinski and Bakker, 1992) choice situations (but see Rowland, 1993). As shown experimentally by Milinski and Bakker (1990), this preference is based almost exclusively on the intensity of the male's red coloration, which reveals his physical condition.

Until now, it has been unknown whether in nature female choice relates to the intensity of the male's red breeding coloration. The objectives of the present study were to investigate in a natural population of sticklebacks (1) this relationship and the influence of the male's physical condition on the expression of red coloration, and (2) the males' breeding behavior.

\section{MATERIALS AND METHODS}

Study population

During the summer (1 1 June-18 August) of 1991, we made almost daily observations of a freshwater population of three-spined sticklebacks (Wohlensee, near Berne, Switzerland, 46 $57^{\prime}$ N, 7²8' E). (During about half the days of June and July, observations were limited due to the turbidity of the water caused by rainfall and snow melting in the Alps.) This population reproduces at the shallow banks of the dammed-up river Aare. It is a polymorphic population with respect to lateral plate count (Bakker TCM and Mundwiler B, unpublished data) and likely introduced at least 15 years ago. The study sites were three lengths of bank, a few hundred meters apart, where reproductive activities of males were clustered. Because migration among study sites is probably limited (Bakker and Mundwiler, unpublished data), they may represent subpopulations of the Wohlensee population.

\section{Male characteristics}

We localized courting males with the aid of a dummy of a ripe female (realistic cast of pewter painted in natural colors) that was fixed in head-up courtship position to a green iron wire and slowly moved through the males' territories. Once localized, we hand-netted the male and put him into a transparent plastic box $(6 \mathrm{~cm} \times 7 \mathrm{~cm} \times 7 \mathrm{~cm})$ containing water. This box had two, high-quality glass windows (Hoya HMC ultraviolet filter, $6 \mathrm{~cm} \times 1.87 \mathrm{~cm}$ ) through which the male could be photographed from two sides. We gently fixed the fish in position against the two windows with a wet, soft, black sponge. We then put the box that contained the male with one of its glass windows over an opening in a transportable, mat-black box containing a camera (Nikon F3 with motor drive and a Nikkor macro lens $105 \mathrm{~mm}$ with macro adapter Nikon PN-I l and an ultraviolet filter Nikon L.97c) and two flashes (Metz $20 \mathrm{BC}$, operating in manual mode) in fixed position. The box containing the male and the front side of the photo-box were covered with a mat- 
black curtain, and slides (Kodak Kodachrome 64 Professional film) were taken from the anterior half of the ventral and one randomly chosen lateral side of the male together with a number of Munsell color cards (details in Frischknecht, 1993).

Before releasing the male at the same site, we measured his (standard) length and weight to calculate his condition factor, $100 \times$ weight $(\mathrm{g}) /$ length $(\mathrm{cm})^{b}$ where $b$ is the slope of the regression of $\log$ (weight) on log(length) (Bolger and Connolly, 1989). To distinguish neighboring males, we marked nearest neighbors by clipping the tip of the first and/or second dorsal spine.

\section{Egg number}

After photographing, we checked males daily for courting activity toward the dummy. When a male was no longer courting, we carefully removed the nest on that day or, depending on the weather conditions and the turbidity of the water, one of the following days, and removed the egg mass and counted all eggs. If counting was impossible without much disturbance, we dabbed the egg mass on absorbent tissue to remove excess water and weighed the mass. We then estimated the number of eggs by extrapolating the weight of a representative sample of a counted number of eggs (usually 20). If possible, we caught the male and kept him in a bucket during these manipulations and released him after the nest and the eggs had been put back in the same place with the same orientation. All males went back to their nests after the manipulation. Only about $20 \%$ of the nests of localized males could be traced and were accessible to us.

\section{Quantification of coloration}

We analyzed the male breeding colors on the slides with a densitometer (X-Rite 310 Photographic Densitometer) connected to a computer. In the red throat region, the optical density of red $(R$, filter $700 \mathrm{~nm})$, green $(\mathrm{G}$, filter $546.1 \mathrm{~nm})$, and blue (B, filter $435.8 \mathrm{~nm}$ ) was measured at 10 defined points $(0.5 \mathrm{~mm}$ diam). With this system the quantification of coloration is limited to the visible light spectrum: ultraviolet light cannot be measured with the applied filters in the densitometer, and will not be adequately registered due to limitations in the photographic system, even without the use of ultraviolet filters (see above). The windows in the box containing the male and the protection of the objective lens consisted of ultraviolet filters because UV filters satisfy the criteria of high-quality glass with known transmission spectrum and cause minimal interference with the visible light spectrum in our system. The densitometer data were corrected for differences in film development by subtracting the optical density of $R, G$, or B of a white Munsell card (N 9.5) visible on each slide (Kodric-Brown, 1989). An appropriate measure of the intensity of red, which is independent of the brightness of a color, is the red index (Frischknecht, 1993), in which the corrected $R$ value is expressed relative to the total color density $(R+G+B)$. Because $R$, $G$, and $B$ are measured as optical density rather than transmissions, when subtracted from 1, positive values between 0 and 1 are obtained. The advantage of the red index is that a white signal will have a smaller value than a red signal, so using the red index avoids the problems of confounding increasing brightness with increasing chroma ("saturation" or color intensity). We calculated the red index for each of the 10 points at the throat and used the highest index in the analyses.

This method of measuring color intensity may be less accurate than measuring intensity directly from the fish (Endler, 1990, 1991). Advantages of our procedure are that changes in coloration caused by handling (that is, changes in color intensity and expansion; in sticklebacks these can quickly change) and changes in survival are minimized. Additionally, there was good correlation between the measured red index and personal judgment from observations of the maximal intensity of red on the jaw (Frischknecht, 1993). Subjective scores of red intensity were furthermore good predictors of female choice (Milinski and Bakker, 1990).

A final proof of the reliability of our method of measuring color intensity was obtained by a direct comparison of the red index with chroma calculated from reflectance spectra. We made the comparison with 15 individually housed, reproductively active males from Rhode Island and Long Island, New York, USA. In the week preceding the color measurements, we regularly stimulated the males (at least two times a day for $15 \mathrm{~min}$ ) with a ripe female enclosed in a plexiglass cell. After 1 weck of intensive stimulation, all males were actively courting, and their colors stabilized. We then photographed the throat of each male using our standard procedure and directly measured reflectance. Before and after each measurement, we stimulated the male with a ripe female for 10-15 min. Photographing and scanning were separated by about $\mathrm{l} \mathrm{h}$, and half the males were photographed first and the other half were scanned first. The reflectance spectrum of the most intensely colored 2.5 $\mathrm{mm}^{2}$ patch on the male's throat (which was dabbed beforehand with absorbent tissue) was measured using the beam method (Endler, 1990); a tungsten light source was used, barium sulfate was used as reflectance standard, and scanning was done with a Spectron CE395 fast spectral scanner (Baube CL, Phillips JB, and Loew ER, in preparation). We calculated chroma from the reflectance spectra (108 points sampled between 400 and $700 \mathrm{~nm}$ converted to quantum flux) using the absorbance spectra for the two primary stickleback photoreceptors (absorbance maxima are 529 and $590 \mathrm{~nm}$, respectively; microspectrophotometry data from Baube et al., in preparation; Endler, 1990, 1991). Because the size of the directly scanned patch was many times greater than the size of the spot on the slides analyzed with the densitometer, we used the mean red index of the 10 measured points on the throat in the comparison rather than the highest index of red. Mean red index ranged from 0.700 to 0.789 , and chroma ranged from 0.184 to 0.342 . There was a good correlation between mean red index and chroma (Spearman rank correlation coefficient $r_{\mathbf{s}}$ $=.80, N=15, p=.0029$, two-tailed). After further regular stimulation over the next 6 days, we repeated the measurement of the reflectance spectra of the males' throats. One male was left out of the analysis because he gave up nesting. Six days later chroma ranged from 0.179 to 0.279 and did not significantly deviate from the earlier measurements 


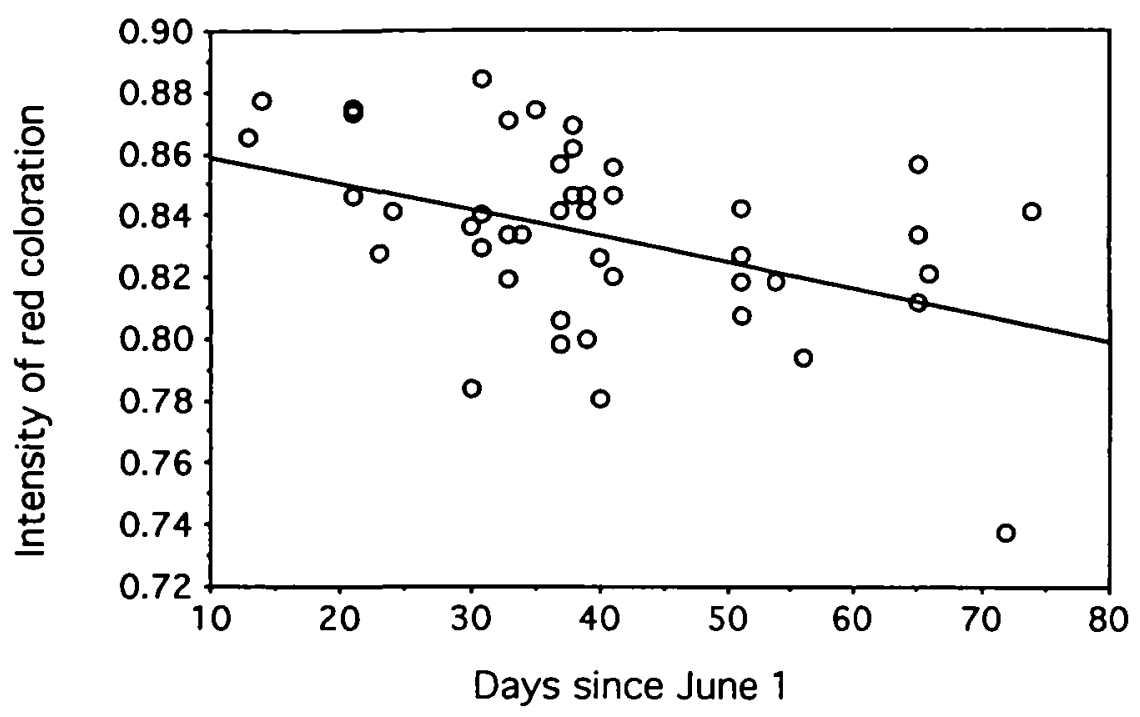

Figure 1

Decrease in the intensity of red breeding coloration of reproductively active males in the Wohlensee population during the breeding season of $19916=0.86688-$ $0.00085 x, r^{2} \square .17, N=45, F$ $=8.79, \mathrm{df}=1,43, p<.005$, two-tailed).

\section{Figure 2}

Correlation between the maximum intensity of red breeding coloration on the throat and the number of eggs in the nest in the Wohlensee population when the influence of date of assessment and duration of parental care are kept constant $(y=-12.03+$ $3004.80 x, r^{2}=.47, N=8, F$ = 5.36, df $=1,4, p<.05$, one-tailed).
(Wilcoxon matched-pairs, signed-ranks test, $N=$ $14, p>.25$, two-tailed). The repeated measurements of chroma correlated well $\left(r_{s}=.82, N=14\right.$, $p=.003$, two-tailed).

The red breeding coloration of male sticklebacks becomes visible at the bottom of the mouth, often long before the start of the breeding season (Wootton, 1976). Around the time of nest building, red colors first appear on the throat and may from there extend caudally (up to the caudal fin) and dorsally (up to about the ventral one third of the body) during a period of 1-2 weeks (Wootton, 1976). The development of blue eyes parallels that of red coloration (McLennan and McPhail, 1989; Wootton, 1976). The extension and intensity of red coloration varies within individuals across the breeding cycle (McLennan and McPhail, 1989) and within and among populations (e.g., Giles and Huntingford, 1985; Reimchen, 1989). Within a given male, the extension and intensity of red colors may change rapidly and are maximally displayed during courtship (McLennan and McPhail, 1989). Because melanophores are lacking on the throat, the red coloration there cannot be masked, unlike it can on other parts of the body (McLennan and

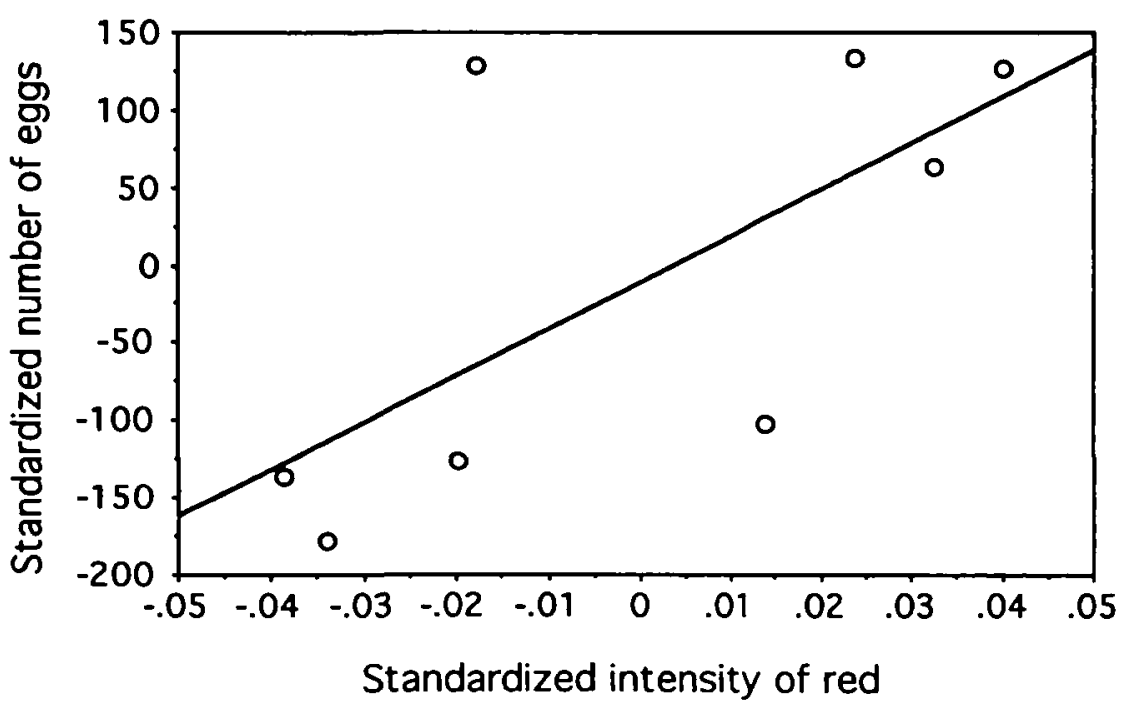

McPhail, 1989). In our study population, the maximum index of red on the throat of reproductively active males ranged from 0.738 to 0.884 .

\section{Data analysis}

Because the data were collected during a period of 3 months and the variables showed a more or less pronounced linear change (mostly a decrease) over time, the influence of date of assessment was partialled out by linear regression analysis. The effect of date was well described by linear regression, as quadratic regression did not yield a higher coefficient of determination $\left(r^{2}\right)$ than linear regression. Thus, we used residual values in the analyses and reduced the degrees of freedom by one, unless stated otherwise. We analyzed the relationship between intensity of red coloration and number of eggs in the nest using untransformed data because their distributions did not significantly deviate from normality [Kolmogorov-Smirnov test, $D=0.171$, $N=12, p$ (Lilliefors) $=.471$, two-tailed, and $D=$ $0.089, N=45, p$ (Lilliefors) $=.471$, two-tailed, for egg number and red intensity, respectively].

\section{Female preference in the laboratory}

During the summer of 1991 , we caught some females from between the vegetation along the banks of the Wohlensee using a long hand net and stored them in the laboratory (light cycle $16 \mathrm{~h}$ light/ $/ 8 \mathrm{~h}$ dark, temperature $15^{\circ} \mathrm{C}$ ) in a 100 -l tank. When they became ripe, we put the females in a plexiglass cell $(11 \mathrm{~cm} \times 7.5 \mathrm{~cm}$, water level $16 \mathrm{~cm})$ and offered them a choice between two courting males that differed in intensity of red coloration (using the same experimental design as in Milinski and Bakker, 1990). We scored female choice as evidenced by the duration of head-up courtship display while pointing to one of the males for a 2-min period after 1 min of acclimatization. The duration of headup display correlates positively with the probability to spawn with that specific male (McLennan and McPhail, 1990).

After the choice test, we kept females individually in 10-1 tanks and counted the number of eggs in spontaneously laid clutches. Because female sticklebacks spawn all ripe eggs at once (Wootton, 1976), spontaneously laid clutches could be used to estimate average clutch size of the Wohlensee population.

\section{RESULTS}

Intensity of red coloration and mating success

Some males $(N=11)$ were localized for the first time after they had become parental. Nest content $(N=6)$ and coloration $(N=9)$ were assessed simultaneously in these cases. As the maximum intensity of red on the throat did not seem to differ between courting and caring males (Mann-Whitney $U$ test, $N_{1}=36, N_{2}=9, Z=0.341, p>.73$, twotailed; see also McLennan, 1991), these males were pooled in the following analysis. The red breeding coloration of reproductively active males became on average less intense later in the breeding season (Figure 1). The number of eggs in a parental male's nest ranged from 20 to $732.1(N=12$, mean \pm 
$\mathrm{SD}=302.8 \pm 209.1$, and the average number of collected eggs showed no significant change over the season $\left(r^{2}=.10, N=12, F=1.16\right.$, $\mathrm{df}=1,10$, $p>.30$, two-tailed). When corrected for date of assessment, the more intense a male's red coloration on his throat, the more eggs he received $\left(r^{2}\right.$ $=.55, N=8, F=7.41$, df $=1,5, p<.025$, onetailed).

Because eggs were counted between 1 and 4 days after the males had stopped courting and eggs may be lost for various reasons during the parental cycle, this correlation must also be corrected for the variable period of paternal care till the time of egg counting. The age of eggs in nests that were first localized after the male had become parental were set at 5 or 6 days. This estimation was based on the time needed to hatch a representative sample of eggs from each nest in the laboratory at $15^{\circ} \mathrm{C}$ compared with the time needed to hatch samples of eggs of known age. There was a significant, negative influence of the duration of parental care before eggs were counted on the number of eggs in the nest (corrected for date of assessment, $r^{2}=.61, N$ $=12, F=15.55, \mathrm{df}=1,10, p<.002$, one-tailed), but there seemed to be no influence of the duration of parental care on the red index of the male (corrected for date of assessment, $r^{2}=.22, N=8, F$ $=1.71, \mathrm{df}=1,6, p>.23$, two-tailed). The eggs of less brightly colored males were not counted at a more advanced age than those of redder males (red corrected for date of assessment, $r^{2}=.26, N=8$, $F=2.09, \mathrm{df}=1,6, p>.19$, two-tailed). When the influence of the duration of paternal care is kept constant by using residuals from a regression analysis, there remains a significant, positive correlation between the male's intensity of red coloration and the number of eggs in his nest (Figure 2).

\section{Female preference}

Further support for a female mating preference for more intensely red males in this population came from simultaneous female choice experiments in the laboratory using eight wild-caught females from the Wohlensee population. The females were tested with one out of two available pairs of males; relative to the red index of the dullest-colored male in each pair, the males of the two pairs differed $2.02 \%$ and $5.99 \%$, respectively, as to their red indexes. The preference among females for the redder male increased significantly with increasing difference in intensity of red between the males $\left(r^{2}\right.$ $=.68, N=8, F=12.73$, df $=1,6, p<.01$, onetailed). The wild-caught females that were used in the choice experiments measured on average 4.9 $\mathrm{cm}(N=8, \mathrm{SD}=0.4$, range $4.4-5.4 \mathrm{~cm})$ and produced an average clutch size of 112.9 eggs ( $\mathrm{SD}=$ 46.1 , range 50-182 eggs).

\section{Number of breeding cycles}

The reproductive males measured on average 4.6 $\mathrm{cm}(N=65, \mathrm{SD}=0.3$, range $4.0-5.2 \mathrm{~cm})$. Courting Wohlensee males were on average shorter (Figure 3a) and lighter (Figure 3b) later in the breeding season. Their average condition, however, remained unchanged over the season (Figure 3c). These findings suggest the succession of different, reproductively active males in this population. Fur-
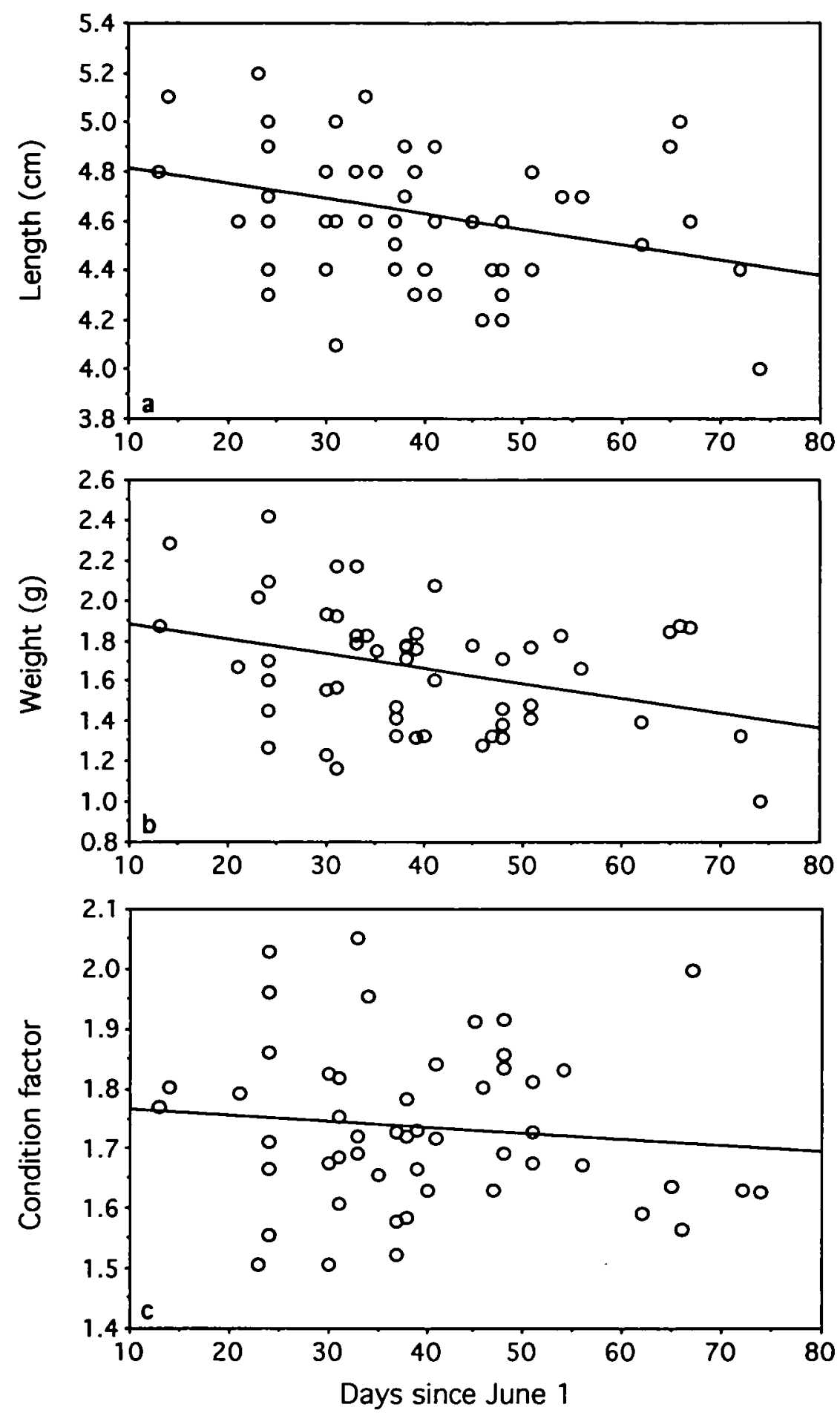

Figure 3

Changes in (a) standard length (in $\mathrm{cm}, y=4.878-0.006 x, r^{2}=.10, N=54, F=6.09$, df $=1,52, p<.017$, two-tailed), (b) weight (in $g . y=1.952-0.007 x, r^{2}=.12, N=52, F=$ $6.68, \mathrm{df}=1,50, p<.013$, two-tailed), and (c) condition factor $(100 \times$ weight $(\mathrm{g}) /$ /ength $(\mathrm{cm})^{297}, y=1.775-0.001 x, r^{2}=.01, N=52, F=0.60$, df $=1,50, p>.44$, two-lailed) of courting males in the Wohlensee population during the breeding season of 1991 .

thermore, only 1 out of 51 nesting males that had been marked was recaptured while nesting a second time at the same length of bank but at a different location than in his earlier breeding cycle. These data suggest that the majority of males in this population complete only one breeding cycle. 


\section{Figure 4}

Cumulative number of newly localized, reproductively active males over the breeding season of 1991 at the study sites (a) Aumatt and (b) Eymatt. The open bars indicate days at which no observations were made and/ or observations were impossible due to great turbidity of the water.

\section{Figure 5}

Correlation between the condition factor $[100 \times$ weight $(\mathrm{g}) /$ length $\left.(\mathrm{cm})^{308}\right]$ and the maximum intensity of red breeding coloration on the throat in courting males of the Aumatt study site when the influence of date of assessment is kept constant $(y$ $=0.0015+0.1011 x, r^{2}=$ $.22, N=17, F=4.32$, df $=$ $1,14, p<.09$, one-tailed).
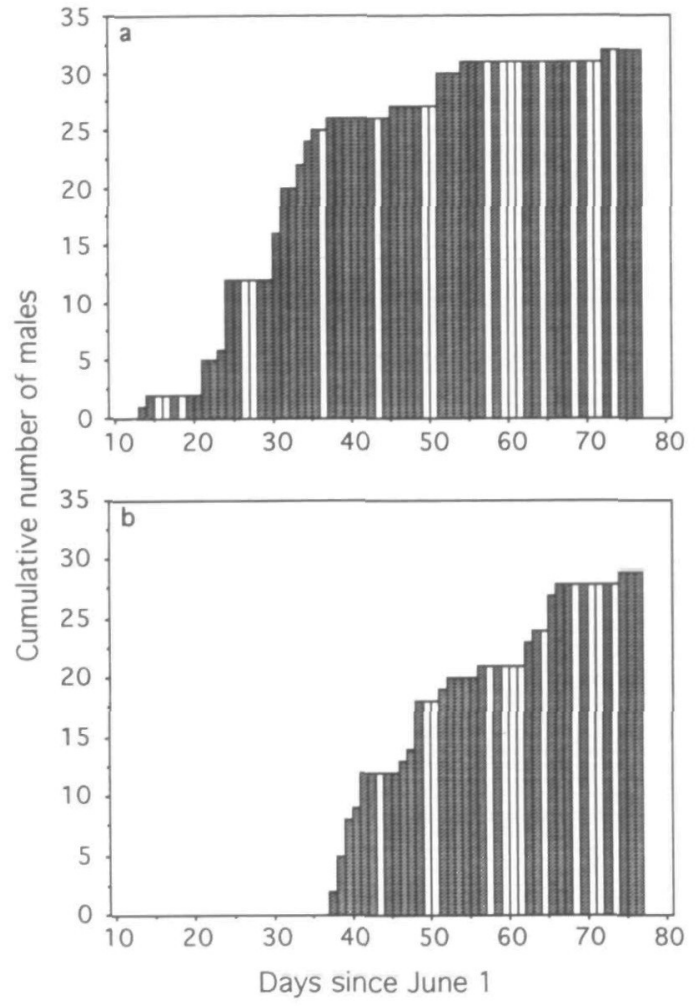

The males' breeding activities were more or less synchronized: during certain periods of time, which lasted up to 1 week, many new reproductively active males could be localized, whereas in the 1-2 weeks after these periods hardly any new reproductively active males were found. At the Aumatt study site, we observed four synchronized breeding cycles (Figure 4a), and three at the Eymatt study site, where we started our observations in July (Figure 4b).

\section{Intensity of red coloration and condition}

For the entire Wohlensee population, there was only a small, insigmificant trend that redder males were in better condition (courting males, data corrected for date of assessment, $r^{2}=.03, N=34, F$

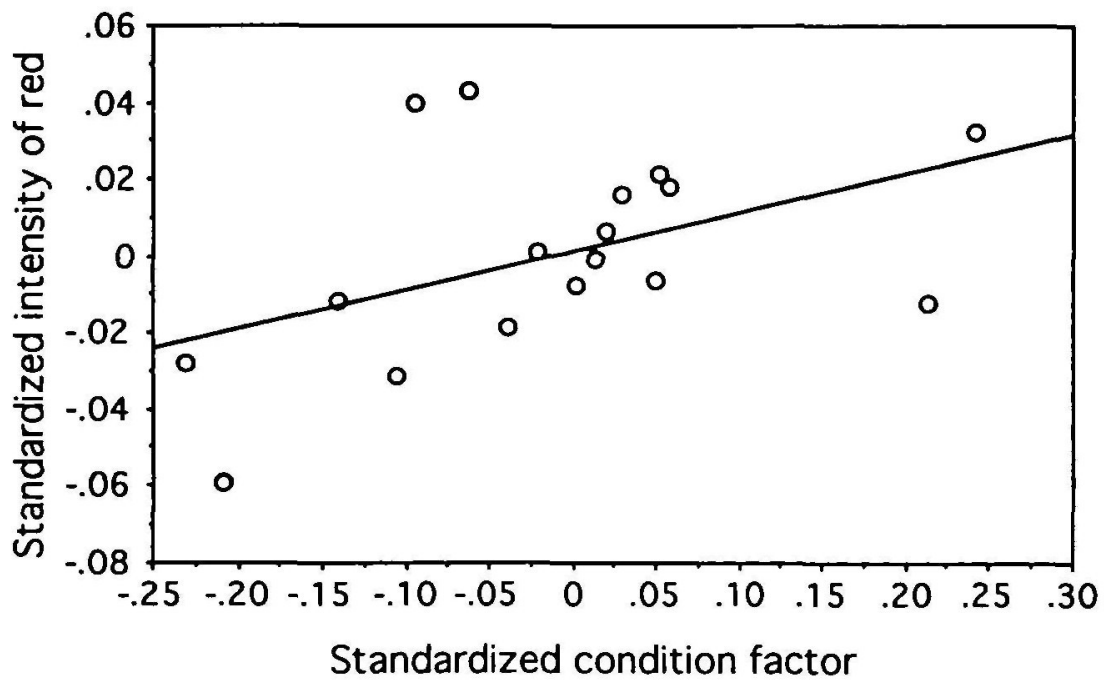

$=1.13$, df $=1,31, p>.13$, one-tailed). Because the study sites differed in a number of biotic and abiotic factors that may affect coloration and condition, the relationship between coloration and condition was analyzed separately for two of the three breeding sites.

Males of the Aumatt site built their nests mainly between stones, under overhanging sedge plants (Carex elata), or in protected spaces under the bank, whereas males of the Eymatt site mainly bred inside or along a small strip of reed (Phragmites australis). The water current was less strong at the Eymatt site due to a broad $(30 \mathrm{~m})$, shallow bank region; this site had a more diverse and rich invertebrate life, and the population density of male sticklebacks was probably higher here.

Reproductively active males tended to be redder at the Eymatt site than at the Aumatt site (data corrected for date of assessment, Mann-Whitney $U$ test, $N_{1}=18, N_{2}=23, Z=1.813, p<.07$, twotailed). When the two study sites were analyzed separately, more intensely red-colored males were significantly in better condition at the Aumatt site (data corrected for date of assessment; Figure 5). This was not the case at the Eymatt site (courting males, data corrected for date of assessment, $r^{2}=$ $.02, N=15, F=0.26$, df $=1,12, p>.30$, onetailed).

\section{DISCUSSION}

This is the first field study with sticklebacks in which male breeding coloration has been quantified and related to sexual selection. Our findings agree with those obtained in the laboratory (Bakker and Milinski, 1991; Milinski and Bakker, 1990, 1992). In nature, intensely red-colored males are also more attractive to ripe females and, in at least one of the study sites, in better condition.

The relationships we established in the field are of a correlative nature, as often is the case in field studies on sexual selection and the independent variables must be experimentally manipulated to rule out the influence of confounding variables. Unfortunately, in fish, experimental manipulation of sexual ornamentation in the field is more restricted, as it is, for example, in birds (e.g., Andersson, 1982; Evans and Hatchwell, 1992; Hill, 1991; Møller, 1988, 1992). Sticklebacks are suitable study objects both in the field and in the laboratory. Therefore, based on the results of experiments in the laboratory (Milinski and Bakker, 1990), the attractiveness of redder males in the field can be attributed to the red coloration itself.

Because eggs had been fertilized for some time before they were counted, the positive correlation between the intensity of red and egg number cannot simply be interpreted as redder males being more attractive to ripe females. The number of eggs in the nest decreased significantly across parental males with the age of the eggs, indicating that eggs are lost during the parental phase. Reasons for egg loss may be cannibalism by the father (Rohwer, 1978) or by other conspecifics (FitzGerald, 1991), stealing of eggs by neighboring males (van den Assem, 1967), heterospecific predation, and mortality caused, for instance, by insufficient ventilation of the eggs (van den Assem, 1967). For our analysis 
we assumed that egg loss rate was unrelated to the males' red coloration. Redder males, however, might have fathered their offspring better (that is, ate less of their own eggs, defended them better, or ventilated them better), which may be one of the reasons for their greater number of eggs (cf. Knapp and Kovach, 1991). This possibility cannot be ruled out without further experimentation. Female choice experiments in the laboratory suggested, however, that females of this population also preferred redder males, indicating that at least part of the positive correlation between red intensity and egg number may be attributable to the greater attractiveness of redder males.

The intensity of red coloration correlated positively with the males' condition at one study site, but at an other site they were not correlated. The relationship between the expression of sexual ornamentation and physical condition is apparently not very stringent (cf. Wedekind, 1992). Although in Milinski and Bakker's study (1990), variance in condition explained $44 \%$ of the variance in the intensity of red coloration, at the Aumatt site this figure was 22\% (Figure 5). In another study with sticklebacks, only changes in condition over time were reflected in the intensity of red (Frischknecht, 1993)

We found no influence of being parental or the length of the paternal care period on the maximum intensity of red on the throat. Perhaps the rate of fading of the red (which is due to carotenoids; Brush and Reisman, 1965; Czeczuga, 1980; Frischknecht, 1993; Matsuno and Katsuyama, 1976) is sufficiently long that the energetics of parental care (Sargent and Gross, 1986) are not strong enough to affect the red over a single breeding cycle. The unchanged maximum of red throat color may point to the value of this signal during the parental phase in attracting additional females and/or defending the territory and nest against intruders. Most other aspects of coloration are changing when males become parental; the male's back and body darkens, and the overall intensity and distribution of red body color decreases (McLennan and McPhail, 1989). Our finding needs additional confirmation, however, because the number of males was limited and the comparison made between males.

The duration of the breeding season would allow individual males to complete at least four or five breeding cycles if they renested immediately after completing a parental cycle (Wootton, 1984). However, males that nested late in the season were on average smaller and less brightly colored than males that nested earlier, although their conditions were comparable. Additionally, only 1 out of 51 reproductive males that had been marked was recaptured during a second breeding cycle. These results suggest that the majority of males in this population complete only one breeding cycle, as was also found in some other stickleback populations (FitzGerald et al., 1986; Kynard, 1978). Of course, the relatively larger and redder males at our study sites that had nested early in the season might have gone to other places to breed, but then one would expect larger and redder males that had completed a breeding cycle elsewhere to invade the study sites to breed. This was apparently not the case. The smaller males that nested later in the season probably belonged to the same age class as early-nesting males. Their size and/or condition may have prevented them from becoming reproductive early in the season. The synchronization of breeding activities (see also Kynard, 1978; Mori, 1990; van Mullem, 1967) in our population, which may be controlled by changes in the turbidity of the water, may increase competition for breeding territories. Raising young likely lowers a male's condition (Sargent and Gross, 1986), and therefore males that just finished a breeding cycle may be inferior competitors.

In conclusion, in this field study, we showed that female sticklebacks prefer to mate with more intensely red-colored males, which were in one of the study sites in better physical condition, thereby confirming laboratory findings of mate choice in this species. The potential reproductive rate of male sticklebacks is probably not achieved under natural conditions because most males seem to complete only one breeding cycle.

We thank Manfred Milinski for stimulating discussions and comments on the manuscript. Comments from Ingtid Ahnesjō and John Endler were greatly appreciated. Thanks are also due to Markus Frischknecht for help in developing a portable stickleback photo-studio and analyzing color slides and to Claus Wedekind for making the dummies. Bill Rowland generously provided laboratory facilities, a stimulating environment, and sticklebacks to T.C.M.B. at Indiana University, and Charles Baube very kindly allowed use of the equipment to measure the reflectance spectra of stickleback throats and unpublished microspectrophotometry data of stickleback cones (grants NY195409 and ONR/N00014-86-K-0619 to E. R. Loew). We thank the Swiss National Science Foundation and the Swiss Academy of Science for financial support.

\section{REFERENCES}

Andersson M, 1982. Female choice selects for extreme tail length in a widowbird. Nature 299:818-820.

Bakker TCM, Milinski M, 1991. Sequential female choice and the previous male effect in sticklebacks. Behav Ecol Sociobiol 29:205-210.

Bolger T, Connolly PL, 1989. The selection of suitable indices for the measurement and analysis of fish condition. J Fish Biol 34:171-182.

Brush AH, Reisman HM, 1965. The carotenoid pigments in the three-spined stickleback, Gasterasters aculeatus. Comp Biochem Physiol 14:121-125.

Czecauga B, 1980. Carotenoids in fish. XXVI. Pungitius pungitius (L.) and Gasterasteus aculeatus L. (Gasterosteidae). Hydrobiologia 74:7-10.

Endler JA, 1990. On the measurement and classification of colour in studies of animal colour patterns. Biol J Linn Soc 41:315-352.

Endler JA, 1991. Variation in the appearance of guppy color patterns to guppies and their predators under different visual conditions. Vision Res 31:587-608.

Evans MR, Hatchwell BJ, 1992. An experimental study of male adomment in the scartet-tufted malachite sunbird: 11. The role of the elongated tail in mate choice and experimental evidence for a handicap. Behav Ecol Sociobiol 29:421-427.

FitzGerald GJ, 1991. The role of cannibalism in the reproductive ecology of the threespine stickleback. Ethology 89:177-194.

FitzGerald GJ, Gaudreault A, Van Havre N, 1986. Decision making by parental sticklebacks Gasterosteus aculeatus in a variable environment. In: Behavioral ecology and population biology (Drickamer LC, ed). Toulouse: Privat; 71-75.

Frischknecht M, 1993. The breeding colouration of male 
three-spined sticklebacks (Casterasteus aculealus) as an indicator of energy investment in vigour. Evol Ecol 7: 439-450.

Giles N, Huntingford FA, 1985. Variability in breeding biology of three-spined sticklebacks (Gastetosteus aculeatus): problems with measuring population differences in aggression. Behaviour 93:57-68.

Goldschmidt T, Bakker TCM, 1990. Determinants of reproductive success of male sticklebacks in the field and in the laboratory. Neth J Zool 40:664-687.

Hill GE, 1991. Plumage coloration is a sexually selected indicator of male quality. Nature 350:397-339.

Knapp RA, Kovach JT, 1991. Courtship as an honest indicator of male parental quality in the bicolor damselfish, Stegastes partitus. Behav Ecol 2:295-300.

Kodric-Brown A, 1989. Dietary carotenoids and male mating success in the guppy: an environmental component to female choice. Behav Ecol Sociobiol 25:393401 .

Kynard BE, 1978. Breeding behavior of a lacustrine population of threespine sticklebacks (Gasterosters aculeatus L.). Behaviour 67:178-207.

Matsuno T, Katsuyama M, 1976. Comparative biochemical studies of carotenoids in fishes-XI. Carotenoids of two species of flying fish, mackerel pike, killifish, three-spined stıckleback and Chinese eight-spined stickleback. Bull Jpn Soc Sci Fish 42:761-763.

McLennan DA, 1991. Integrating phylogeny and experimental ethology: from pattern to process. Evolution 45:1773-1789.

McLennan DA, McPhail JD, 1989. Experimental investigations of the evolutionary significance of sexually dimorphic nuptial colouration in Gasterasteus aculeatus (L.): temporal changes in the structure of the male mosaic signal. Can J Zool 67:1767-1777.

McLennan DA, McPhail JD, 1990. Experimental investigations of the evolutionary significance of sexually dimorphic nuptial colouration in Gasterosteus aculeatus (L.): the relationship between male colour and female behaviour. Can J Zool 68:482-492.

Milinski M, Bakker TCM, 1990. Female sticklebacks use male coloration in mate choice and hence avoid parasitized males. Nature 344:390-933.
Milinski M, Bakker TCM, 1992. Costs influence sequential mate choice in sticklebacks, Gasterosteus actleatus. Proc R Soc Lond B 250:229-233.

Møller AP, 1988. Female choice selects for male sexual tail ornaments in the monogamous swallow. Nature 392:640-642.

Maller AP, 1992. Female swallow preference for symmetrical male sexual ornaments. Nature 357:238-240.

Mori S, 1990. The breeding system of the three-spined stickleback, Gasterosteus aculeatus (leiurus form), with reference to spatial and temporal pattern of nesting activity (PhD dissertation). Kyoto, Japan: Kyoto University.

Reimchen TE, 1989. Loss of nuptial color in threespine sticklebacks (Gasterosterus aculeatus). Evolution 43:450460.

Rohwer S, 1978. Parent cannibalism of offspring and egg raiding as a courtship strategy. Am Nat 1 12:429-440.

Rowland WJ, 1993. Proximal determinants of stickleback behavior: an evolutionary perspective. In: The evolutionary biology of the threespine stickleback (Bell MA, Foster SA, eds). Oxford: Oxford University Press (in press).

Sargent RC, Gross MR, 1986. Williams' principle: an explanation of parental care in teleost fishes. In: The behaviour of teleost fishes (Pitcher TJ, ed). London: Croom Helm; 275-293.

van den Assem J, 1967. Territory in the three-spined stickleback, Gasterasteus aculeatus L. An experimental study in intra-specific competition. Behaviour Suppl $16: 1-164$

van Mullem PJ, 1967. On synchronization in the reproduction of the stickleback (Gasterasterss aculeatus L. forma leiura Cuv.). Arch Néerl Zool 17:258-274.

Wedekind C, 1992. Detailed information about parasites revealed by sexual ornamentation. Proc R Soc I ond B 247:169-174.

Wootton RJ, 1976. The biology of the sticklebacks. London: Academic Press.

Wootton RJ, 1984. A functional biology of sticklebacks. London: Croom Helm. 